\title{
Mapping spatial dimensions of Wilderness recreation outcomes: a study of overnight users
}

\author{
Erinn Drage, William L. Rice, Zachary D. Miller, Jennifer N. Newton, Ashley D’Antonio, Peter Newman \& \\ B. Derrick Taff
}

Keywords: outdoor recreation, outcomes-focused management, PPGIS, spatial dimensions

\section{Abstract}

Grand Teton National Park (GRTE) is a popular mountain recreation destination which, like many National Park Service (NPS) units, has experienced a significant increase in visitation in recent years, with total visits increasing by $27 \%$ between 2014 and 2017 (NPS 2020). Particularly popular within GRTE is the String and Leigh Lakes (SLL) area, which is a favoured alpine destination for numerous day-use recreation activities and also an important starting point for backcountry and overnight recreational users within GRTE's Recommended Wilderness. To better understand the visitor experience of overnight backcountry recreationists in the SLL area, data were collected using novel public participatory geographic information systems (PPGIS) during the summer of 2018.

PPGIS data were used to identify the locations in which overnight recreationists experienced positive and negative recreation outcomes. Results indicate that they experience more positive outcomes within the Recommended Wilderness, away from high-density, trailhead-proximate areas outside the Recommended Wilderness. Findings also indicate that overnight users experience crowding and conflict more outside of the Recommended Wilderness than elsewhere on their backcountry trip. While this may seem intuitive, these are some of the first empirical results spatially contextualizing backcountry visitor outcomes in a popular national park. The findings thus provide managers with a visitor experience baseline that can be monitored and adaptively managed in the future.

\section{Profile}

Protected area

Grand Teton National

Park

Mountain range

Teton Range, Rocky

Mountains

Country

U.S.

\section{Introduction}

Over the last century, recreation management in parks and protected areas (PPAs) in the United States has changed significantly as managers have attempted to adjust to the growing diversity of conflicting visitor expectations, recreation goals and social values (Lee \& Driver 1992; Newsome et al. 2008; Vaske et al. 2007). As visitor trends and management issues within PPAs change, national park administrators must adopt innovative monitoring and management strategies to attend to the expectations of visitors and the need to protect natural resources (White et al. 2016). Various data are needed to inform management strategies, allowing for a better understanding of the changing political, social and natural landscapes of PPAs (Graefe et al. 1984). As research techniques advance with technology, spatial methods are becoming especially relevant in PPA studies seeking to understand the social conditions of parks, including incorporating public participation in the mapping of social values (Beeco \& Brown 2013). As new methods are developed and become feasible for field research, the spatial dimensions of various recreational activities are becoming more exact, more available, and thus more useful to managers in understanding visitor recreation outcomes correctly (Riungu et al. 2018). Despite a growing body of literature and an improved understanding of how best to manage for the social values and benefits derived from recreation, very few studies have explored the spatial dimensions of backcountry overnight recreationist outcomes (i. e. of overnight stays in particularly remote areas). Building on public participatory geographic information systems (PPGIS) methodology, this study therefore offers spatial representations of overnight backcountry visitors' outcomes in Recommended Wilderness (which by National Park Service policy is managed in the same way as federally designated Wilderness), and specifically in the String and Leigh Lakes (SLL) area as a case study.

\section{Research purpose}

Using PPGIS and building on Outcomes-Focused Management as a PPA managerial framework, this research seeks to answer the question: how are the positive and negative outcomes experienced through overnight backcountry recreation, within or outside the Recommended Wilderness boundary, distributed across the String and Leigh Lakes area? 


\section{Literature review}

\section{Outcomes-focused management}

For decades, researchers and protected area managers have been grappling to find the most effective ways of meeting visitors' needs while managing for the potential social and environmental impacts of park visitation (Eagles 2001). A clear understanding of the outcomes achieved by visitors to national parks helps managers to deliver on National Park Service mandates and achieve effective Wilderness management. Several social science methods used to understand visitor experiences have been proposed since the 1970s, with visitors' goals, preferences and benefits emerging as important components of management frameworks (Lee \& Driver 1992). One management framework that was quickly adopted by protected areas management agencies in the United States was Benefits Based Management (BBM), an approach to recreation management proposed by Lee and Driver (1992). Unlike previous recreation management approaches, BBM did not focus on recreation activities and settings as the starting point for management, but sought to identify the benefits derived from recreation activities, and the specific activities and settings which could potentially procure these benefits (Lee \& Driver 1992; McCool et al. 2007).

More recently, Driver (2008) proposed OutcomesFocused Management (OFM) as a new research and management model that expands on its precursor, BBM, to address some of its shortcomings. One of the most distinguishing characteristics of OFM is its ability to focus on both positive and negative outcomes of recreation experiences (Driver 2008). OFM maintains that visitors have preferences for certain experiences because they believe that engaging in a specific experience leads to the attainment of a goal or outcome (Driver 2008). To fully understand visitor experiences in PPAs, visitor preferences and the positive outcomes they seek, along with the negative outcomes that may be experienced during recreation, are crucial information for managers. Because overnight visitors may be more sensitive to negative outcomes including crowding (Pierce \& Manning 2015), managers may benefit from a better understanding of where overnight recreationists experience positive and negative outcomes. Despite the benefits to be derived from understanding visitor outcomes, spatial data explicitly linking visitor experience outcomes to specific locations, resources or features is lacking; yet these data are extremely important both to advance OFM and for adaptive management of PPAs through applied science.

Spatial dimensions of outdoor recreation and participatory mapping

When it comes to parks and recreation management, spatial data are important for understanding the distribution of PPA visitors, impacts on natural resources, and where recreation experiences may be negatively impacted (D'Antonio \& Monz 2016). Likewise, because so much of PPA management is done in a spatial context, a spatial understanding of visitor perspectives on recreation and the use of PPAs is important to ensure the holistic management of social and natural resources (Beeco \& Brown 2013). Spatial representations of outdoor recreational activities collected through a variety of mapping methods have been shown to help managers measure the social, environmental, cultural and managerial impacts of visitors to protected areas by demonstrating the locations people visit, their travel routes, and the amount of time spent at particular locations (Hallo et al. 2012).

In recent years, the importance of understanding the spatial dimensions of visitor conditions in PPAs has become increasingly clear. One method with noteworthy potential to be applied to social science research is PPGIS, through which spatial data are provided directly by study participants who identify locations on a digital or physical map (Riungu et al. 2018). This approach allows visitors to highlight place attributes based on their own understanding of a park, thereby revealing their unique perceptions, place knowledge and experiences (Brown et al. 2015). In an attempt to add to the understanding of the spatial dimensions of recreation experiences, public participatory mapping is used in recreation social sciences research (Beeco \& Brown 2013; Van Riper et al. 2012). Using public participatory mapping, spatial dimensions can be overlaid with conventional social variables, such as visitors' values, benefits, goals and outcomes. In this way, PPGIS has the potential to bridge the gap between the way that PPA visitors feel about space and place, and the science-based management of natural and recreational resources.

While PPGIS has been used in recreation planning and management in recent years to better understand visitor distribution, recreational activities, conservation priorities and place values (Brown, Raymond \& Corcoran 2015), there have been only a few applications of PPGIS to visitor outcomes. Recently, Wolf, Brown and Wohlfart (2017) used PPGIS and GPS methods to identify perceived crowding and visitor conflicts between mountain bikers and horseback riders in Australia. They found the application of PPGIS to crowding research to be effective in identifying trails used by different visitor groups, and to show promise for predicting areas of conflict. The researchers postulated that innovative methods such as PPGIS will be essential in the future to identify and manage conflicts along multi-use trails (Wolf et al. 2017). Beeco et al. (2014) also used spatial methods, including GIS and GPS data, to map visitors' preferences and to create recreation suitability models for competing recreation activity groups. Using GPS tracking of visitors to compare and contrast visitor use patterns and preferences, they concluded that combining spatial data with conventional social science methods was 


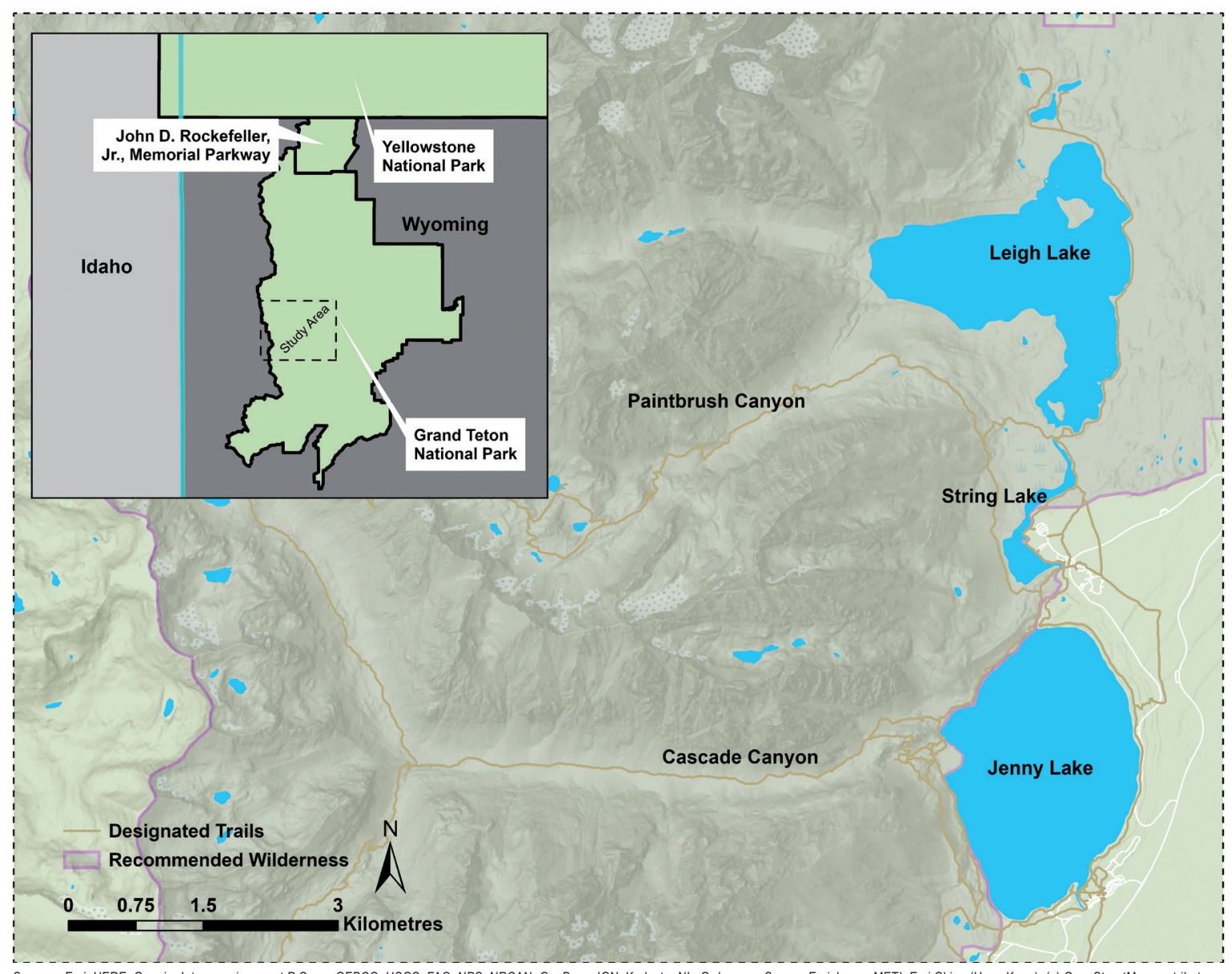

Sources: Esri, HERE, Garmin, Intermap, inrement P Corp., GEBCO, USGS, FAO, NPS, NRCAN, GeoBase, IGN, Kadaster NL, Ordanance Survey, Esri Japan, METI, Esri China (Hong Kong), (c) OpenStreetMap contributors, and the GIS User Community, Sources: Esri, Airbus DS, USGS, NGA, NASA, CGIAR, N Robinson, NCEAS, NLS, OS, NMA, Geodatastyrelsen, Rijkswaterstaat, GSA, Geoland, FEMA, Intermap and the GIS user community

Figure 1 - The study area within Grand Teton National Park, Wyoming.

useful for informing visitor management. Similarly, Pietilä (2017) used spatial methods to measure positive visitor outcomes in Oulanka National Park in Finland. In this study, Pietilä used an online PPGIS survey to assess how visitor experiences differ across park settings, contributing important insights into the benefits of PPGIS for understanding visitor outcomes. Additionally, Beeco and Brown (2013) conducted an in-depth review of the application of spatial data to social sciences and management in PPAs. They noted the novelty of the integration of spatial and social science methods, calling for the increased incorporation of spatially relevant data in the field of PPA social science research. They also noted that while literature has been emerging on the importance and value of spatial data for recreation managers, few studies have offered a spatial visualization of visitor outcomes. To date, no previous research has applied PPGIS to analyse both positive and negative outcomes through an OFM design, leaving an important gap in the research. Furthermore, there is a lack of this type of research within the Wilderness-focused literature. This study therefore uses PPGIS to assess outcomes achieved by overnight backcountry users within and outside the Recommended Wilderness boundaries in GRTE's SLL area, thus contributing a better understanding of the spatial dimensions of OFM in a backcountry setting. In doing so, this paper answers the question: How does the spatial distribution of overnight users' positive outcomes compare to the distribution of their negative outcomes?

\section{Methods}

\section{Study site}

Established in 1929, Grand Teton National Park (GRTE) is a popular US national park that is renowned for its exceptional mountain scenery and abundance of wildlife. At 310000 acres, GRTE protects pristine wildlife habitat, countless ecosystem and recreational services, and the major peaks of the 40-mile long Teton Range. Like many other US National Park Service (NPS) units, GRTE has experienced large increases in visitation in recent years (NPS 2020). Particularly popular within GRTE is the SLL area, which has experienced an increase in visitation in recent years, with approximately 4000 people entering the SLL parking area every day during the summer of 2017 (NPS 2017). Most of the SLL area lies within Federally Recommended Wilderness and is therefore managed in the same way as congressionally designated Wilderness, outlined in the 1964 Wilderness Act. The area of- 


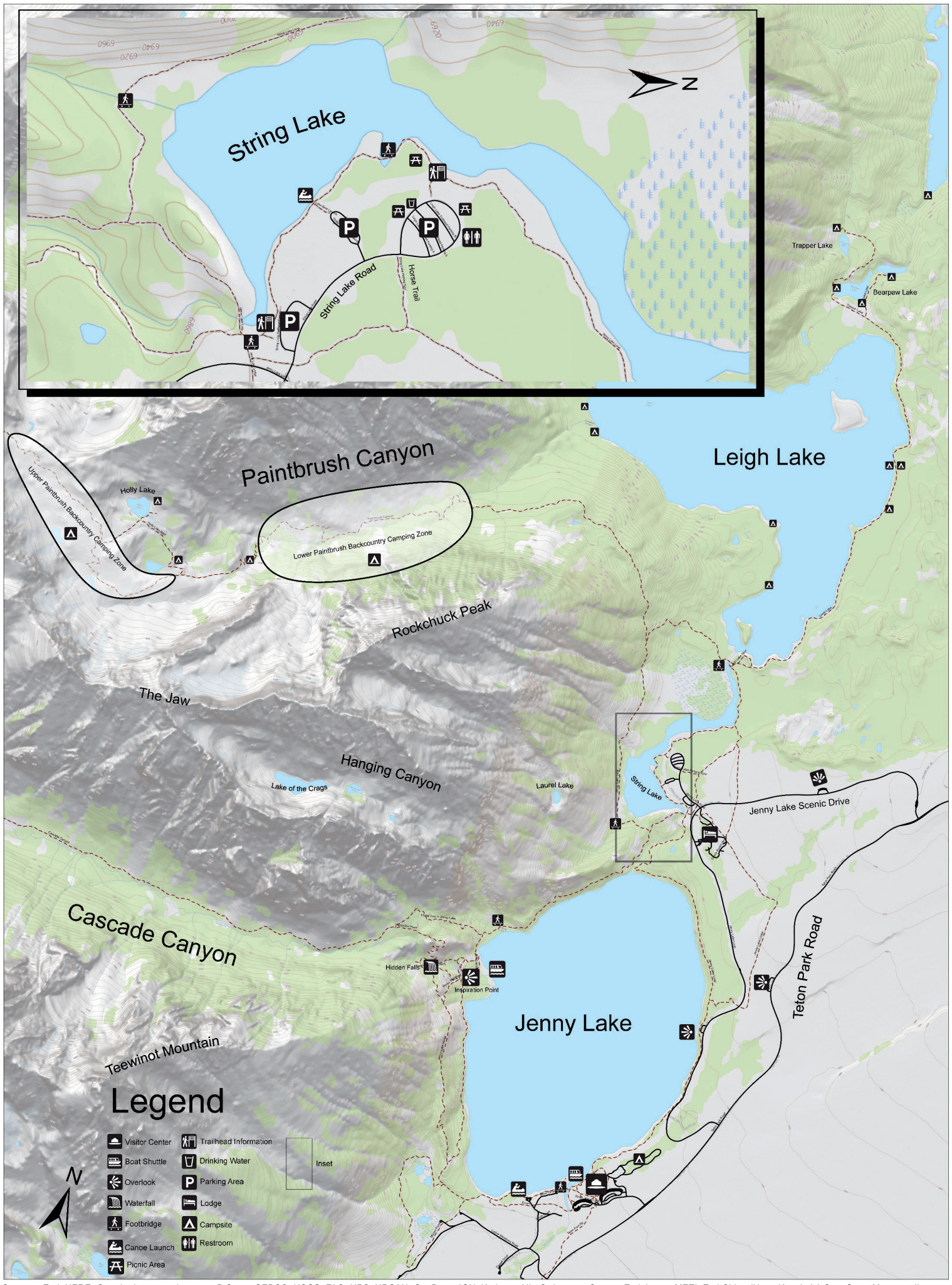

Sources: Est, HLRE, Garmin, Intermap, inrement P Corp., GEBCO, USGS, FAO, NPS, NRCAN, GeoBase, GGN, Kadaster NL, Ordanance Survey, Esri Japan, METI, Esri China (Hong Kong), (c) OpenStreetMap contributors Figure 2 - Map presented to public participatory geographic information system (PPGIS) respondents for the mapping of outcomes.

fers spectacular views of the Teton Range, making it a favoured mountain destination for numerous day-use recreational activities, including paddling, swimming, hiking and picnicking (D'Antonio et al. 2019). The SLL area includes two trailheads leading to numerous hiking trails, designated picnic areas, and a boat launch site for non-motorized watercraft such as canoes, kayaks and stand-up paddleboards. The trailheads in the SLL area are also starting points for backcountry and overnight recreational users, providing access to some of the most popular backcountry destinations in the park, including Paintbrush Canyon, Cascade Canyon 
and Holly Lake (Rice et al. 2019). There are several established backcountry camping zones in Paintbrush Canyon and Cascade Canyon, and campsites on the shores of Holly, Bearpaw, Trapper and Leigh Lakes, within the Recommended Wilderness boundary.

\section{Data collection and analysis}

\section{PPGIS data collection}

Public participatory mapping data were collected from overnight visitors who, for the purpose of this study, included any person who stayed one or more nights in the GRTE backcountry of the SLL area. A combination of convenience sampling and stratified random sampling was used to maximize the sample size (Singh \& Mangat 1996). All data collection took place between 28 June and 12 August 2018, which is a peak-use period for the SLL. Data were collected throughout the day, with sampling shifts taking place from 8:00 am to 4:00 pm, and from 11:00 am to 7:00 pm. From 8:00 am to 7:00 pm, recreationists who demonstrated signs of overnight use of the park (e.g. camping gear, large backpacks, heavily loaded canoes) and / or were confirmed (by an initial screening question) to be exiting a SLL trailhead from an overnight trip in the SLL backcountry, were recruited for the study. One survey was administered per group of visitors through a randomized process in which the adult with the next upcoming birthday was asked to take the survey. The data collection consisted of a short survey collecting demographic data completed on an iPad equipped with Qualtrics survey software, and a short PPGIS activity. For the PPGIS component, participants were given a detailed map of the area (Figure 2) containing place names and topographic features, and asked if during their trip they experienced any of six positive outcomes (improved connection with nature, improved state of mind, improved self-confidence, enhanced sense of adventure, enhanced family togetherness and improved social bonding) or three negative outcomes (crowding, conflict with other visitors and damage of natural resources). If participants did experience any of these outcomes, they were asked to identify on the map the specific location where they perceived the outcome to the greatest extent. Trained research technicians transferred the mapping data collected from visitors on paper into ESRI ArcCollector on an iPad.

\section{PPGIS data analysis}

The distributions of the positive and negative outcomes experienced by overnight users were overlaid and converted to point density-based heat maps using ArcGIS Pro. Several maps were created using these data, including individual point density heat maps (Brown \& Weber 2011) of each positive and negative outcome, and maps of all positive outcomes combined and all negative outcomes combined. These maps were analysed visually and compared to each other to better understand the spatial relationships between
Table 1 - Frequency of reportings of positive and negative outcomes.

\begin{tabular}{|l|r|r|}
\hline Outcome & $\begin{array}{l}\text { Number of } \\
\text { reportings }\end{array}$ & $\begin{array}{l}\text { Portion of total } \\
\text { reportings }\end{array}$ \\
\hline Improved connection with nature & 53 & $17 \%$ \\
\hline Improved state of mind & 46 & $15 \%$ \\
\hline Crowding & 43 & $14 \%$ \\
\hline Enhanced sense of adventure & 41 & $13 \%$ \\
\hline Improved self-confidence & 40 & $13 \%$ \\
\hline Improved social bonding & 32 & $10 \%$ \\
\hline Enhanced family togetherness & 24 & $8 \%$ \\
\hline Conflict & 19 & $6 \%$ \\
\hline Damage of natural resources & 12 & $4 \%$ \\
\hline
\end{tabular}

the positive and negative outcomes of overnight users (Steinberg \& Steinberg 2015). Finally, in an effort to further understand these spatial relationships and to advance the application of PPGIS methodologies to visitor outcomes (e.g., Pietilä 2017), we used percentages of positive and negative outcomes experienced through overnight backcountry recreation within or outside the Recommended Wilderness boundary, distributed across the String and Leigh Lakes area.

\section{Results}

The PPGIS sample size for backcountry overnight respondents was 58, with an overall response rate of $95.1 \%$. Of the 58 survey respondents, 50 identified themselves as backpackers and 8 as canoe/kayak campers. Positive outcomes for backcountry users were reported most densely in the Bear Paw and Trapper Lakes area, and in the vicinity of Holly Lake in Paintbrush Canyon (see Figure 2). All of these destinations within the SLL area have backcountry campsites, and are located several miles from the SLL trailheads and within the Recommended Wilderness boundary. Figure 3 further demonstrates that all of the six positive outcomes were experienced in Paintbrush Canyon, with improved social bonding and improved connection with nature being especially prevalent. In contrast, relatively few positive outcomes occurred along the eastern shoreline of String Lake (a popular area within the park, adjacent to trailheads), which is considered a front country (i. e. readily accessible) area, near Hidden Falls / Inspiration Point, or in Cascade Canyon, which are located within the Recommended Wilderness boundary. Improved connection with nature - the most frequently reported outcome $(17 \%$, Table 1) - resulted in a distinct distribution, with a high density of reports in Cascade Canyon and in the vicinity of Lake of the Crags.

Figure 4 shows where negative outcomes were experienced by overnight users. Conflict with other users and crowding were most often reported in the vicinity of String Lake and in the lower reaches of Paintbrush Canyon and Cascade Canyon, adjacent to or outside the Recommended Wilderness boundary. Meanwhile, 

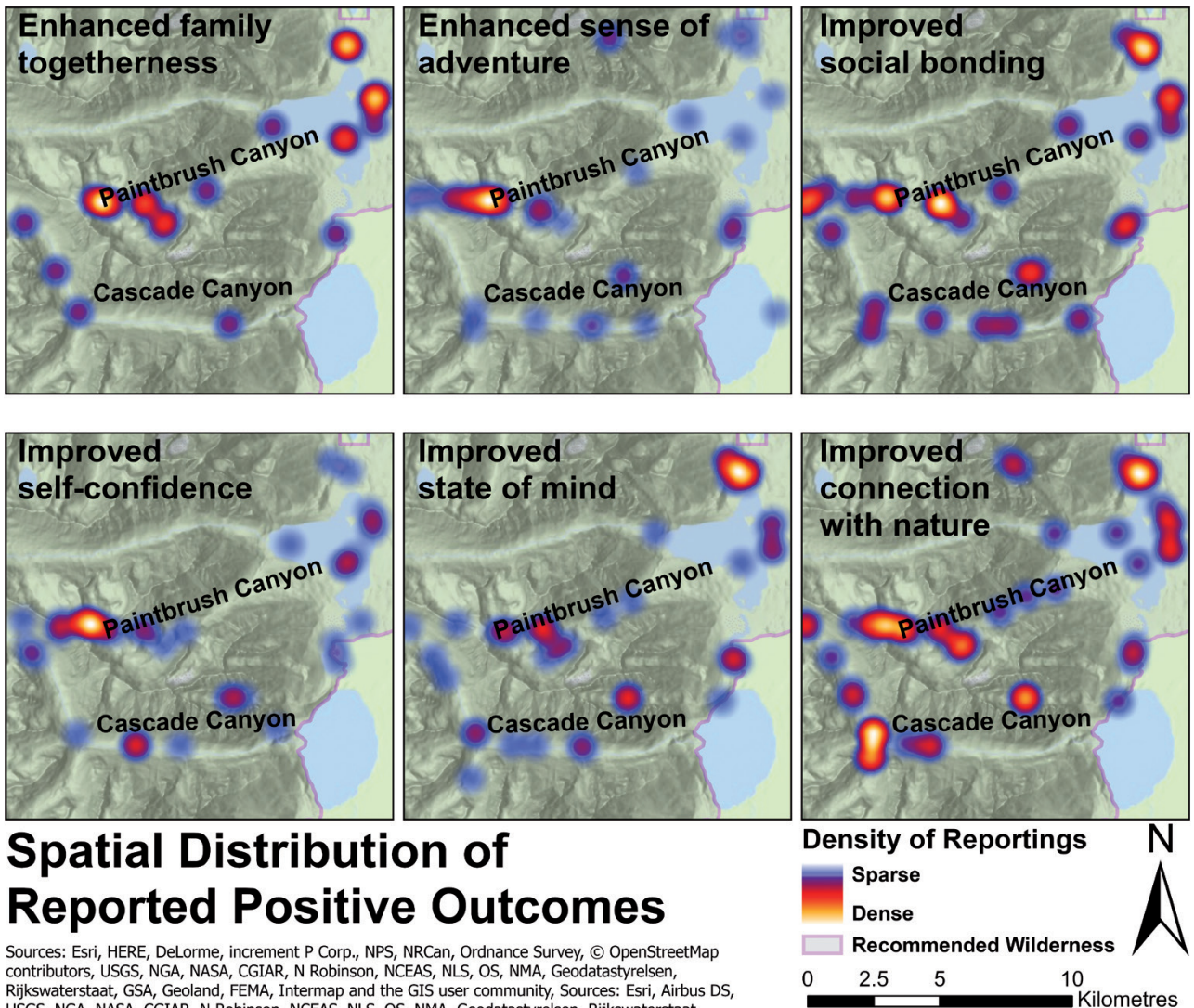

\section{Spatial Distribution of} Reported Positive Outcomes

Sources: Esri, HERE, DeLorme, increment P Corp., NPS, NRCan, Ordnance Survey, @ OpenStreetMap contributors, USGS, NGA, NASA, CGIAR, N Robinson, NCEAS, NLS, OS, NMA, Geodatastyrelsen, USGS, NGA, NASA, CGIAR, N Robinson, NCEAS, NLS, OS, NMA, Geodatastyrelsen, Rijkswaterstaat, GSA, Geoland, FEMA, Intermap and the GIS user community

Figure 3 - Spatial distribution of the 6 positive outcomes reported by overnight users in the String and Leigh Lakes (SLL) area.
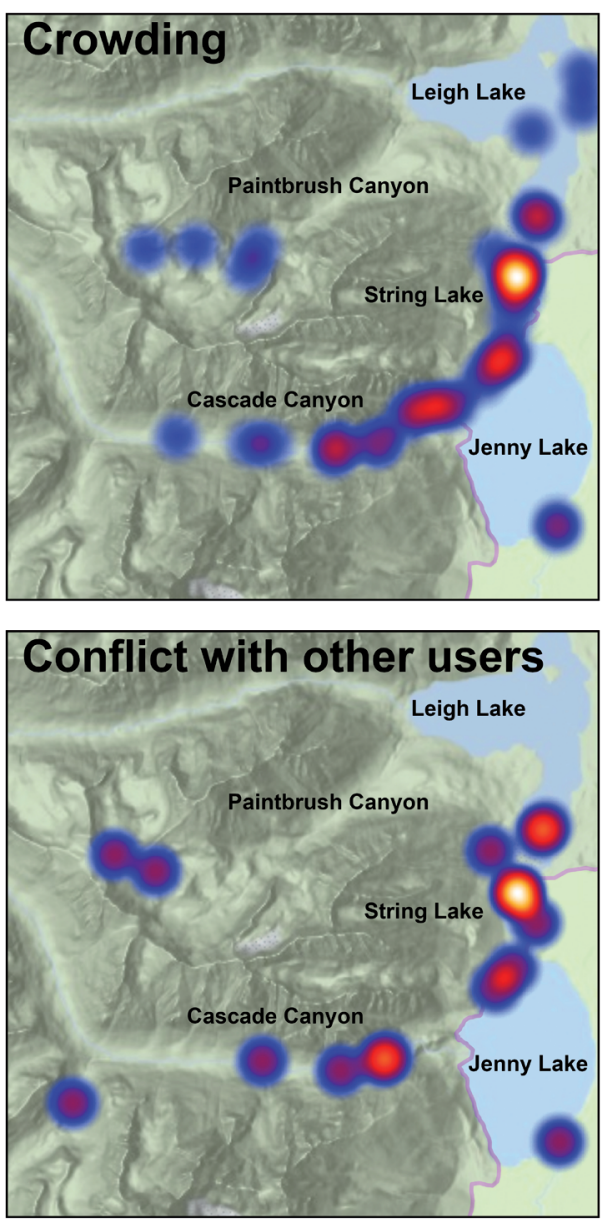

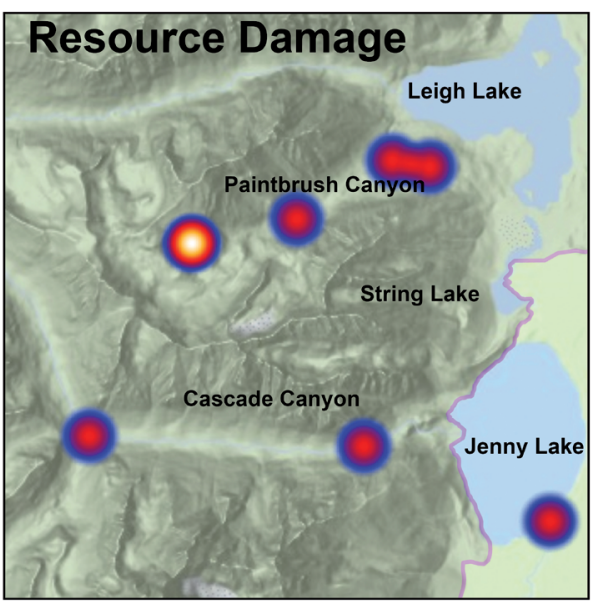

Spatial Distribution of Reported Negative Outcomes

Density of Reportings

Dearse
Rense

$\begin{array}{llll}0 & 2.5 & 5 & 10\end{array}$ Kilometres

Sources: Esri, HERE, DeLorme, increment P Corp., NPS, NRCan Ordnance Survey, O OpenStreetMap contributors, USGS, NGA, NASA CGIAR, N Robinson, NCEAS, NLS, OS, NMA, Geodatastyrelsen, Rijkswaterstaat, GSA, Geoland, FEMA, Intermap and the GIS user community, Sources: Esri, Airbus DS, USGS, NGA, NASA, CGIAR, N GSA, Geoland, FEMA, Intermap and the GIS user community

Figure 4 - Spatial distribution of negative outcomes reported by overnight users. 

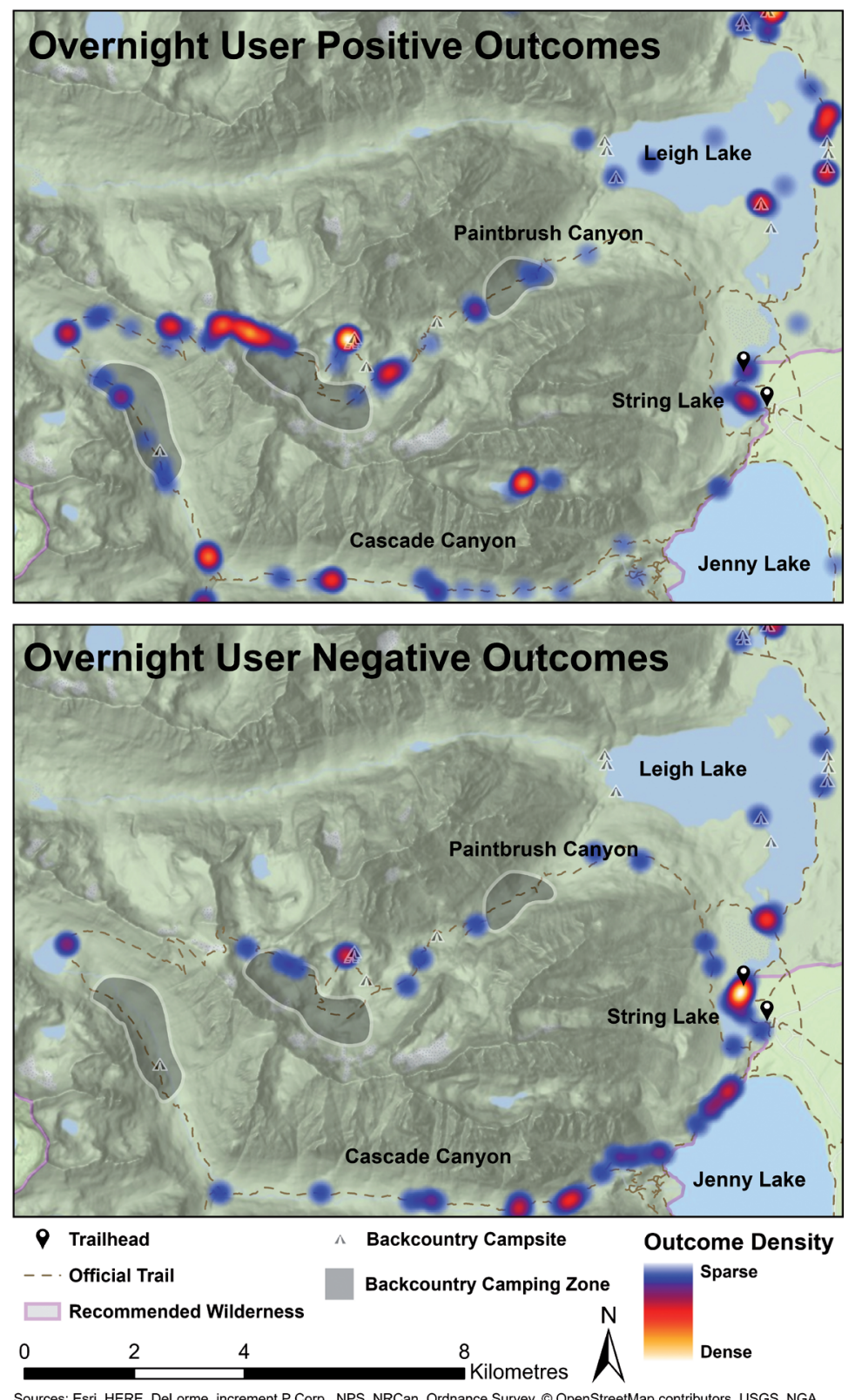

Sources: Esri, HERE, DeLorme, increment P Corp., NPS, NRCan, Ordnance Survey, ๑ OpenStreetMap contributors, USGS, NGA GIS user community, Sources: Esri, Airbus DS, USGS, NGA, NASA, CGIAR, N Robinson, NCEAS, NLS, OS, NMA, Geodatastyrelse GIS user community, Sources: Esri, Airbus DS, USGS, NGA, NASA, CGIAR, N
Rijkswaterstaat, GSA, Geoland, FEMA, Intermap and the GIS user community

Figure 5 - Spatial distributions of positive and negative outcomes reported by overnight users.

resource damage was most commonly reported in Paintbrush Canyon and Cascade Canyon, both within the Recommended Wilderness boundary.

Figure 5 illustrates the combined positive and combined negative outcomes across the study area. Overall, the majority of positive outcomes were reported near campsites or camping zones, and within the Recommended Wilderness boundary. However, Lower Cascade Canyon, the northwest shoreline of Jenny Lake, and the eastern shoreline of String Lake generated the highest densities of negative outcomes for overnight users. These areas are outside the Recommended Wilderness boundary or adjacent to the boundary. To extend the previous outcome-focused management and PPGIS methodologies, Table 2 highlights the percentage differences between positive and negative outcomes experienced within or outside the Recommended Wilderness boundary. Results indicate that more positive than negative outcomes were experienced within the Recommended Wilderness boundary ( $95 \%$ and $82 \%$ respectively).

\section{Discussion and conclusion}

When critically analysing the PPGIS maps of outcomes experienced in the SLL area, it becomes clear that there is a difference between the spatial distributions of overnight users' positive and negative outcomes. This is further highlighted through percentage differences (Figures 3-5 and Table 2). Figures 3-5 demonstrate that overnight users experience negative outcomes in places where they are likely to encoun- 
Table 2 - Distribution of outcomes within and outside the Recommended Wilderness

\begin{tabular}{|l|r|l|}
\cline { 2 - 4 } \multicolumn{1}{c|}{} & $\begin{array}{l}\text { Within Recom- } \\
\text { mended Wilder- } \\
\text { ness }\end{array}$ & $\begin{array}{l}\text { Outside Recom- } \\
\text { mended Wilder- } \\
\text { ness }\end{array}$ \\
\hline Positive outcomes & $95 \%$ & $5 \%$ \\
\hline Negative outcomes & $82 \%$ & $18 \%$ \\
\hline
\end{tabular}

ter other visitors (i. e., in areas close to trailheads outside the Recommended Wilderness boundary), while experiencing positive outcomes further away from trailheads and within the Recommended Wilderness boundary. Positive outcomes were densest in the Bear Paw and Trapper Lakes area, and in the vicinity of Holly Lake in Paintbrush Canyon. Interestingly, some negative outcomes were also reported in these areas. Tables 1 and 2 explicitly highlight these differences, and the occasionally overlapping positive and negative outcomes.

These findings emphasize the difficult dual mandate faced by the National Park Service, to enable quality recreational experiences while protecting the resources that provide those experiences. Damage to natural resources, although reported infrequently compared to the other outcome variables, occurred in some of the same locations where visitors reported positive outcomes. This suggests that some level of natural resource impact may even enhance overnight users' positive experiences (e.g. visitor-created social trails), but begs us to question at what point those impacts caused by recreationists will be so severe that it negates the positive outcomes gained in these locations (Taff et al. 2019). With these results in mind, managers may be able to increase monitoring efforts and management strategies that facilitate the positive outcomes within the SLL area, while potentially mitigating some of the negative outcomes.

This study provides managers with baseline data within and outside the Recommended Wilderness boundary to inform their monitoring of potentially changing social and ecological conditions in the SLL area. Some trends suggest that day-visitors are going further into the backcountry (Papenfuse et al. 2000). If this were to occur in the SLL area, it could interfere with the positive outcomes which overnight visitors gain within the Recommended Wilderness boundary. Continuing to evaluate overnight and day visitors' experiences, both within and outside the Recommended Wilderness boundary, will be particularly important if use of the area continues to increase. These results should enable park management to consider other areas within GRTE that may offer similar outcomes, and to begin monitoring them. For example, if visitation to the SLL area continues to increase, managers can expect other areas within GRTE that potentially offer similar outcomes to see increased use, due to visitors' desires to obtain the same or similar recreational outcomes (Hall \& Shelby 2000). By developing monitor- ing plans for these areas early, managers can proactively implement different measures to address potential impacts on the ecological and social environments.

Because individuals who experience more encounters with others than expected are more likely to feel crowded (Manning 2011), managers have an opportunity to shape visitor expectations and ultimately satisfaction through clear communication strategies. Using theory-based and science-informed messaging, managers may help alleviate perceptions of crowding and increase the perceived quality of the recreation experience (Taff et al. 2014). Furthermore, clear communication efforts can help build realistic visitor expectations, and encourage onsite visitor behaviours that align with the management objectives for the SLL area, both within and outside the Recommended Wilderness boundary.

Finally, this study offers important methodological insight into the spatial dimensions of outdoor recreation, particularly within the context of Wilderness management. Understanding the spatial dimensions of visitors' experiences has been shown to be important in managing visitor preferences in recreation (Beeco \& Brown 2013). By collecting spatial data, managers are better able to fully contextualize the locations of positive and negative outcomes obtained by recreationists. This holds great potential to aid managers in assessing both positive and negative outcomes experienced by visitors to parks and protected areas, especially crowding and displacement (Manning 2011). In this study, PPGIS successfully helped identify the locations of visitor outcomes in the SLL area of GRTE. The potential of integrating more spatial methods with social sciences and management strategies continues to grow as technology that allows for ease of field data collection develops. Future research should consider the application of PPGIS to other backcountry recreation outcomes and contexts of recreation management, considering how further GPS methods may be paired with social sciences data to spatially represent visitor experiences.

\section{Acknowledgements}

Funding for this research was provided by the $\mathrm{Na}$ tional Park Service through a Cooperative Ecosystem Studies Unit agreement. Additional assistance was provided by the AMK Ranch University of WyomingNational Park Service Research Station.

\section{References}

Beeco, J.A. \& G. Brown 2013. Integrating space, spatial tools, and spatial analysis into the human dimensions of parks and outdoor recreation. Applied Geography 38: 76-85.

Beeco, J.A., J.C. Hallo \& M.T. Brownlee 2014. GPS visitor tracking and recreation suitability mapping: 
Tools for understanding and managing visitor use. Landscape and Urban Planning 127: 136-145.

Brown, G., C.M. Raymond \& J. Corcoran 2015. Mapping and measuring place attachment. Applied Geography 57: 42-53.

Brown, G. \& D. Weber 2011. Public Participation GIS: A new method for national park planning. Landscape and Urban Planning 102: 1-15.

Brown, P.J., B.L. Driver \& C. McConnell 1978. The opportunity spectrum concept in outdoor recreation supply inventories: Background and application. Proceedings of the Integrated Renewable Resource Inventories Workshop. USDA Forest Service General Technical Report RM-55: 73-84.

D'Antonio, A. \& C. Monz 2016. The influence of visitor use levels on visitor spatial behavior in off-trail areas of dispersed recreation use. Journal of Environmental Management 170: 79-87.

D’Antonio, A., D. Taff, C. Monz, P. Newman, J.T. Baker, W.L. Rice, S. Freeman \& Z.D. Miller 2019. Leigh and String Lakes visitor use study at Grand Teton National Park: 2018 data collection summary. Report prepared for the US National Park Service.

Driver, B.L. 2008. What is outcomes-focused management? In: Driver, B.L. (ed.), Managing to optimize the beneficial outcomes of recreation: 19-37. State College, PA.

Eagles, P.F. 2001. Evolution of the concept of visitor use management in parks. Industry and Environment 24(3): 65-67.

Graefe, A.R., J.J. Vaske \& F.R. Kuss 1984. Social carrying capacity: An integration and synthesis of twenty years of research. Leisure Sciences 6(4): 395-431.

Hall, T. \& B. Shelby 2000. Temporal and spatial displacement: Evidence from a high-use reservoir and alternative sits. Journal of Leisure Research 32(4): 435-456.

Hallo, J.C., J.A. Beeco, C. Goetcheus, J. McGee, N.G. McGehee \& W.C. Norman 2012. GPS as a method for assessing spatial and temporal use distributions of nature-based tourists. Journal of Travel Research 51(5): 591-606.

Jacob, C.R. \& R. Schreyer 1980. Conflict in outdoor recreation: A theoretical perspective. Journal of Leisure Research 12: 368-380.

Lee, M.E. \& B.L. Driver 1992. Benefits-based management: A new paradigm for managing amenity resources. In: Rickerson, R.E., D.R. Field \& P. Nilson (eds.), Second Canada/US Workshop on Visitor Management in Parks, Forests and Protected Areas; May 13-15, 1992: 143-154. Madison, WI: University of Wisconsin School of Natural Resources.

Manning, R.E. 2011. Studies in outdoor recreation: Search and research for satisfaction. Corvallis, OR.

McCool, S.F., R.N. Clark \& G.H. Stankey 2007. An assessment of frameworks useful for public land recreation planning. Portland, OR: U.S. Department of Agriculture, Forest Service, Pacific Northwest Research Station.

National Park Service 2017. Extremely High Visitation at String Lake Prompts Actions Additional Volunteers Needed. Available at: https://www.nps.gov/ grte/learn/news/ extremely-high-visitation-at-stringlake-prompts-actions-additional-volunteers-needed. htm (accessed 23/09/2020)

National Park Service 2020. National Parks Service Visitor Use Statistics. Annual Park Recreation Visitation, GRTE Report. Available at: https://irma. nps.gov/STATS/Reports/Park/GRTE (accessed 23/09/2020)

Newsome, D., A. Smith \& S.A. Moore 2008. Horse riding in protected areas: A critical review and implications for research and management. Current Issues in Tourism 11: 144-166.

Papenfuse, M.K., J.W. Roggenbuck \& T.E. Hall 2000. The rise of the day visitor in wilderness: should managers be concerned? In: Cole, D.N., S.F. McCool, W.T. Borrie \& J. O'Loughlin (eds.), Wilderness science in a time of change conference: Wilderness visitors, experiences, and visitor management. 148-154. U.S. Department of Agriculture, Forest Service, Rocky Mountain Research Station.

Pierce, W.V. \& R.E. Manning 2015. Day and overnight visitors to the Olympic Wilderness. Journal of Outdoor Recreation and Tourism 12: 14-24.

Pietilä, M. 2017. Do visitor experiences differ across recreation settings? Using geographical information systems to study the setting-experience relationship. Visitor Studies 20(2): 187-201.

Rice, W.L., B.D. Taff, P. Newman, Z.D. Miller, A.L. D’Antonio, J.T. Baker, C. Monz, J.N. Newton \& K.Y. Zipp 2019. Grand expectations: Understanding visitor motivations and outcome interference in Grand Teton National Park, Wyoming. Journal of Park \& Recreation Administration 37(2): 26-44.

Riungu, G.K., B.A. Peterson, J.A. Beeco \& G. Brown 2018. Understanding visitors' spatial behavior: A review of spatial applications in parks. Tourism Geographies 20(5): 833-857.

Singh, R. \& N.S. Mangat 1996. Elements of survey sampling. Dordrecht, Netherlands.

Stankey, G.H. 1977. Some social concepts for outdoor recreation planning. In: Hughes, J.M. \& R.D. Lloyd (eds.), Outdoor recreation: Advances in application of economics: 154-161. Washington, DC: U.S. Department of Agriculture, Forest Service.

Steinberg, S.L. \& S.J. Steinberg 2015. GIS research methods: Incorporating spatial perspectives. Redlands, CA.

Taff, B.D., J. Benfield, Z.D. Miller, A. D'Antonio \& F. Schwartz 2019. The role of tourism impacts on cultural ecosystem services. Environments 6(14). Doi: 10.3390/environments6040043

Taff, B.D., P. Newman, S. Lawson, A. Bright, L. Marin, A. Gibson \& T. Archie 2014. The role of messaging on acceptability of military aircraft sounds in Sequoia National Park. Applied Acoustics 84: 122-128.

Van Riper, C.J., G.T. Kyle, S.G. Sutton, M. Barnes \& B.C. Sherrouse 2012. Mapping outdoor recreationists' perceived social values for ecosystem services at Hinchinbrook Island National Park, Australia. Applied Geography 35(1-2): 164-173. 
Vaske, J.J., M.D. Needham \& J.R.C. Cline 2007. Clarifying interpersonal and social values conflict among recreationists. Journal of Leisure Research 39(1): 182-195.

White, E., J.M. Bowker, A.E. Askew, L.L. Langner, J.R. Arnold \& D.B.K. English 2016. Federal outdoor recreation trends: effects on economic opportunities. Gen. Tech. Rep. PNW-GTR-945. Portland, OR: U.S. Department of Agriculture, Forest Service, Pacific Northwest Station.

Wolf, I.D., G. Brown \& T. Wohlfart 2017. Applying public participation GIS (PPGIS) to inform and manage visitor conflict along multi-use trails. Journal of Sustainable Tourism 26(3): 470-495.

\section{Authors}

\section{Erinn Drage}

is a graduate student in the Department of Recreation, Park, and Tourism Management at Penn State University. Part of the Protected Areas Research Collaborative, her research considers park management, conservation and community engagement in protected areas.

\section{William L. Rice ${ }^{2}$}

is an Assistant Professor in the Department of Society and Conservation at the University of Montana. His research focuses on providing recreational ecosystem services in protected areas and developing tools to help manage visitor demand.

\section{Zach Miller ${ }^{3}$}

is an Assistant Professor at Utah State University and an affiliate of the Institute of Outdoor Recreation and Tourism. He focuses on visitor use management in parks and protected areas, including visitor experiences, human-wildlife relationships and strategic communication.

\section{Jennifer Newton ${ }^{4}$}

is the social scientist at Grand Teton National Park. Her work includes studying visitor use and experience, monitoring visitor use and visitor use related impacts, and providing science-informed management action recommendations.

\section{Ashley D'Antonio 5}

is an Assistant Professor of Nature-based Recreation Management in the College of Forestry at Oregon State University. She is a recreation ecologist; her research programme focuses on using spatial methods to understand visitor behaviour and associated impacts.

\section{Peter Newman}

serves as the Head of the Department of Recreation, Park, and Tourism Management at Penn State University. His research focuses on visitor management, including transportation, protection of natural sounds, social/ecological systems, and links between parks and human health.

\section{Derrick Taff}

is in the Recreation, Park, and Tourism Management Department at Penn State University. His research uses communication to influence behaviours in a manner that promotes positive health outcomes for humans and the environment, within the context of national parks.

1 The Pennsylvania State University, Department of Recreation, Park, and Tourism Management

${ }^{2}$ University of Montana, Department of Society and Conservation

${ }^{3}$ Utah State University, Department of Environment and Society

${ }^{4}$ National Park Service, Grand Teton National Park

${ }^{5}$ Oregon State University, Department of Forest Ecosystems and Society 